\title{
Fosfomycin Therapy for Non-Complicated Lower Urinary Tract Infections during Pregnancy: Tanta University Experience
}

\author{
Ayman Shehata Dawood1*, Abdelghaffar Said Dawood', Salah Abdelmonsef Nagla², \\ Mohamed Abdelatti El-Bakary ${ }^{2}$ \\ ${ }^{1}$ Department of Obstetrics and Gynecology, Tanta University, Tanta, Egypt \\ ${ }^{2}$ Department of Urology, Tanta University, Tanta, Egypt \\ Email: *ayman.dawood@med.tanta.edu.eg
}

How to cite this paper: Dawood, A.S., Dawood, A.S., Nagla, S.A. and El-Bakary, M.A. (2017) Fosfomycin Therapy for NonComplicated Lower Urinary Tract Infections during Pregnancy: Tanta University Experience. Open Journal of Obstetrics and Gynecology, 7, 532-544.

https://doi.org/10.4236/ojog.2017.75056

Received: April 28, 2017

Accepted: May 22, 2017

Published: May 25, 2017

Copyright $\odot 2017$ by authors and Scientific Research Publishing Inc. This work is licensed under the Creative Commons Attribution International License (CC BY 4.0).

http://creativecommons.org/licenses/by/4.0/

(c) (i) Open Access

\begin{abstract}
Objectives: To evaluate the efficacy, compliance, safety and economic cost for Fosfomycin trometamol and Nitofurantoin in uncomplicated lower urinary tract infections during pregnancy. Background: Nitofurantoin and Fosfomycin trometamol are recommended as the first-line agents for treatment of urinary tract infections (UTIs) in the latest guidelines endorsed by the Infectious Diseases Society of America (IDSA) and the European Society for Clinical Microbiology and Infectious Diseases (ESCMID). Fosfomycin is bactericidal and inhibits bacterial cell wall biogenesis and reduces bacterial adherence to uroepithelial cells. Fosfomycin has broad antibacterial activity against both Grampositive and Gram-negative pathogens, as Escherichia coli, Escherichia faecalis, and various Gram-negatives like Citrobacter and Proteus. Both Nitofurantoin and Fosfomycin are category $B$ in pregnancy. Patients and Methods: This study was conducted at Tanta University Hospitals in the period from June, 1, 2015 to January, 1, 2017. Patients were recruited from outpatient clinics of Obstetrics and Gynecology and Urology Departments presenting with asymptomatic bacteruria or cystitis. Patients were allocated randomly into 2 groups: group I ( $\mathrm{n}=50$ cases) received Fosfomycin therapy and group II $(\mathrm{n}=$ 50 cases) received Nitofurantoin therapy ( $\mathrm{n}=50$ cases). After treatment, evaluation of patient symptoms, organism count, patient compliance and cost of treatment were done. Results: The enrolled patients were suffering from lower urinary tract infections; asymptomatic bacteruria (17 cases) or cystitis (83 cases). Ten patients were excluded. The demographic data of included patients were not significant for both groups. Complete relief (100\%) of symptoms 5 days after start of treatment was noticed in Fosfomycin group while improvement of symptoms after 5 day-treatment was noticed in $86.49 \%$ in Nitofurantoin group ( $\mathrm{p}$-value $=0.030$ ). The side effects were recorded in 7 cases $(18.42 \%)$ in Fosfomycin group compared to (35.14\%) with significant
\end{abstract}


difference in the reported side effects, $(\mathrm{p}$-value $=0.003)$. Compliance was $38 / 38$ (100\%) in Fosfomycin group compared to $34 / 37$ (91.89\%) in Nitrofuantoin group $(\mathrm{p}$-value $=0.001)$. Resistance was very minimal in Fosfomycin group where $1 / 38$ case $(2.63 \%)$ reported resistance for treatment compared to $8 / 37$ cases $(21.62 \%)$ in Nitofurantoin group (p-value $=0.001$ ). Conclusion: Fosfomycin trometamine proved to be safe, effective, and has limited resistance. Moreover higher patient compliance and fewer side effects were recommending Fosfomycin to be a first choice drug for uncomplicated lower urinary tract infections during pregnancy at Tanta University.

\section{Keywords}

Fosfomycin, Nitofurantoin, Pregnancy, UTIs, Asymptomatic Bacteuria, Cystitis

\section{Introduction}

Urinary tract infection (UTI) is considered the most commonly occurring bacterial infection in women [1]. Urinary tract infections (UTIs) complicate 3\% to $10 \%$ of pregnancies and are among the commonest reasons for antibiotic use in obstetrics. Uncomplicated lower UTI is usually defined as acute cystitis occurring with no known abnormalities of the urological tract, and is characterized by symptoms such as dysuria, urgency, frequency, suprapubic pain and/or haematuria [1] [2].

Escherichia coli is the leading organism responsible for uncomplicated UTI (82.5\%), while other entero-bacteria (e.g. Proteus mirabilis, Klebsiella pneumoniae), Staphylococcus saprophyticus and Enterococcus faecalis are also commonly implicated [3] [4].

Enterobacteriaceae has been the production of enzymes, known as betalactamases, capable of inactivating some members of the penicillin and cephalosporin class antibiotics, which share a similar beta-lactam chemical ring structure. Most recently extended-spectrum beta-lactamase (ESBL) enzymes have arisen, which cause resistance not only to penicillins and cephalosporins, but also additional resistance to fluoroquinolones, aminoglycosides, and sulfamethoxasoletrimethoprim, and are known as multidrug-resistant organisms (MDROs) [5] [6].

Antibiotic resistance has affected disease management in our specialty. Increased resistance of Neisseria gonorrhea to penicillins and quinolones, emergence of methicillin-resistant staphylococcus aureus (MRSA) and resistance of Group B Streptococcus to erythromycin and clindamycin have led us to modify our antibiotic treatment regimens [5] [6] [7].

Fosfomycin trometamol $\left[\right.$ Monuril $\left.{ }^{\circledR}\right]$ is FDA approved (category B) in numerous countries worldwide, mainly for the treatment of uncomplicated urinary tract infections (UTIs). Fosfomycin has good in-vitro activity against common uropathogens, including Gram positive and negative organisms such as Escherichia coli (including extended-spectrum $\beta$-lactamase-producing E. coli), Proteus mirabilis, Klebsiella pneumoniae and Staphylococcus saprophyticus [8] [9] [10].

Fosfomycin trometamol given in a single oral dose of $3 \mathrm{~g}$ achieves high concentrations in urine and is generally well tolerated. The most reported side ef- 
fects were gastrointestinal (e.g. diarrhoea, nausea) and vaginitis [8] [9] [10].

Results of recent randomized trials showed that single-dose fosfomycin trometamol had similar clinical and/or bacteriological efficacy to 3-7-day regimens of ciprofloxacin, norfloxacin, cotrimoxazole or nitrofurantoin in women with uncomplicated lower UTIs [9] [10] [11]. In addition, single-dose Fosfomycin trometamol had similar bacteriological efficacy to a 7-day course of combined antibiotic regimens [11] [12] [13].

In this study, we compared the efficacy of single dose $3 \mathrm{~g}$ orally versus the conventional oral Nitrofurantoin in non-complicated lower urinary tract infections during pregnancy at Tanta University Hospitals.

\section{Patients and Methods}

\subsection{Study Design}

A prospective, non-blinded, randomized controlled clinical trial.

\subsection{Study Settings}

This study was conducted at Tanta University in both departments of Obstetrics and Gynecology and department of Urology in the period from June, 1, 2015 to January, 1, 2017.

\subsection{Recruitment}

Hundred patients between 12 - 36 weeks of gestation were enrolled in this study according to the following inclusion criteria: a) Uncomplicated lower UTIs (asymptomatic bacteruria or cyctitis); b) Patient in whom culture revealed an antibiotic contraindicated with pregnancy. The exclusion criteria were for patients with a) History of congenital urogenital anomalies; b) Cases associated with hydronephrosis due to any cause; c) Urinary stones; d) Diabetic and immune-compromised patients; e) Patients with high grade fever associated with flank pain and/or signs of pyelonephritis; f) Patients with severe nausea and/or vomiting and are unable to receive oral medication.

\subsection{Sample Calculation}

The sample was calculated by Epi info 0.7 programs with 2 sided confidence level $95 \%$ at power of $85 \% . \mathrm{H}_{0}$ postulated to denote that Fosfomycin is superior to Nitofurantoin. The estimated sample was 100 patients.

\subsection{Randomization and Allocation}

Patients were allocated randomly into 2 groups. Randomization was done by specific computerized program and alternate allocation for both groups. Group I ( $n=50$ cases): patients received oral Fosfomycin single dose therapy. Group II ( $\mathrm{n}=50$ cases) received oral Nitrofurantoin.

\subsection{Dosage and Administration}

Fosfomycin trometamin sachet was dissolved into half a cup of water and taken 
before bed time. Patients should empty their bladder, and then took the dissolved Fosfomycin before bedtime.

Nitrofurantoin $100 \mathrm{mg}$ was given in capsule form three times daily for 7 days.

\subsection{Methods}

All patients age, parity, gestational age, and symptoms plus abdomen /pelvis ultrasonography and urine analysis, were taken at the beginning of the study. After 7 days, questionnaire for symptoms relief, compliance, and complications plus a second urine analysis for counts of organisms. Results were recorded for both groups.

Questionnaire was simply designed and specified by authors' collaboration. It was made of 3 sections: The first section, considered demographic data of participants, the second sections, considered patients' presentation, symptom relief, residual symptoms, compliance and costs of treatment. The third section evaluated the efficacy of treatment by second urine analysis findings and occurrence of side effects and specifying these side effects (Appendix I).

\subsection{Ethical Approval}

This study was obtained before the start of treatment under the code 31242/ 12/16 by Tanta University Ethical committee.

\subsection{Statistical Analysis}

It was done using SPSS version 18, USA. The statistical tests used were mean, standard deviation, Chi square $\left(\mathrm{x}^{2}\right)$ and $\mathrm{p}$-value. Significance is positive if $\mathrm{p} \leq 0.05$.

\section{Results}

One hundred patients were enrolled in this study from Urology and Obstetrics and Gynecology Departments, Tanta University, Egypt. All patients were suffering either asymptomatic bacteruria (17 cases) or cystitis ( 83 cases). Ten patients were excluded because they were either not meeting inclusion criteria ( 7 cases) or declined to participate ( 3 cases). The flow chart of enrolled patients is demonstrated in Figure 1.

The mean patient's age was $28.5 \pm 3.4$ years in group I and $27.9 \pm 4.02$ years in group II. The mean gravidity was $(1.2 \pm 0.3$ and $1.3 \pm 0.4)$ for group I and II respectively. The mean parity was $(1.7 \pm 0.4$ and $1.9 \pm 0.9)$ for group I and II respectively. The mean BMI was ( $23.7 \pm 3.2$ and $22.8 \pm 2.4)$ for group I and II respectively. The mean gestational age at presentation was (33.4 \pm 1.7 and $34.01 \pm$ 1.23) for group I and II respectively. The demographic data of included patients were not significant for both groups Table 1 .

Efficacy of the 2 drugs Fosfomycin and Nitrofurantoin was evaluated by subjective improvement of symptoms where 38/38 (100\%) were symptom-free 5 days after start of treatment in Fosfomycin group. Improvement of symptoms after 5 day-treatment was noticed in $32 / 37(86.49 \%)$ in Nitrofurantoin group, $(\mathrm{p}$-value $=0.030)($ Table 2$)$. 


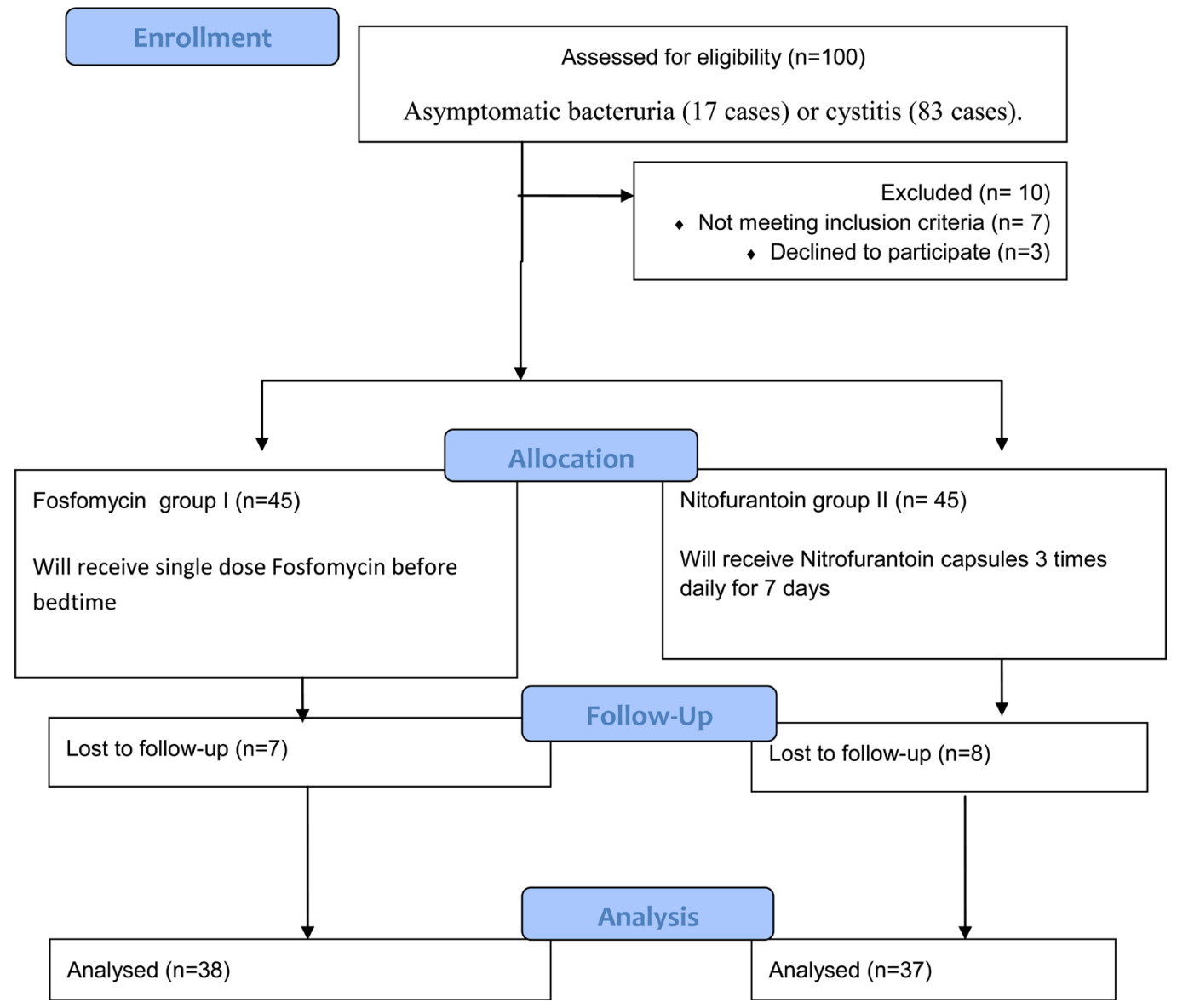

Figure 1. Flow chart of included patients and their management options.

Table 1. Demographic data and presentation of enrolled patients.

\begin{tabular}{|c|c|c|c|c|}
\hline & $\begin{array}{l}\text { Group I } \\
\text { Fosfomycin } \\
(\mathrm{N}=38)\end{array}$ & $\begin{array}{c}\text { Group II } \\
\text { Nitrofurantoin } \\
\quad(\mathrm{n}=37)\end{array}$ & $\mathrm{X}^{2}$ & $\mathrm{p}$ value \\
\hline \multicolumn{5}{|l|}{ Age (years) } \\
\hline Range & $22.4-35.6$ & $21.8-34.9$ & 2.122 & 0.064 \\
\hline Mean \pm SD & $28.5 \pm 3.4$ & $27.9 \pm \quad 4.02$ & & \\
\hline \multicolumn{5}{|l|}{ Gravidity } \\
\hline Range & $1-5$ & $1-6$ & 1.230 & 0.073 \\
\hline Mean \pm SD & $1.2 \pm \quad 0.3$ & $1.3 \pm \quad 0.4$ & & \\
\hline \multicolumn{5}{|l|}{ Parity } \\
\hline Range & $0-5$ & $0-5$ & 1.039 & 0.080 \\
\hline Mean \pm SD & $1.7 \pm 0.4$ & $1.9 \pm \quad 0.9$ & & \\
\hline \multicolumn{5}{|l|}{ BMI } \\
\hline Range & $19.34-27.71$ & $20.06-27.12$ & 3.124 & 0.120 \\
\hline Mean \pm SD & $23.7 \pm 3.2$ & $22.8 \pm \quad 2.4$ & & \\
\hline \multicolumn{5}{|l|}{ Gestational age at presentation } \\
\hline Range & $22.5-35.4$ & $23.2-36.6$ & 7.88 & 0.839 \\
\hline Mean \pm SD & $33.4 \pm 1.7$ & $34.01 \pm 1.23$ & & \\
\hline \multicolumn{5}{|l|}{ Presentations } \\
\hline Cystitis & $31(81.58 \%)$ & $30(81.08 \%)$ & 11.304 & 0.451 \\
\hline Asymptomatic bacteruria & $7(18.42 \%)$ & $7(18.92 \%)$ & 2.409 & 0.297 \\
\hline
\end{tabular}


A second urine sample was done 7 days after start of treatment where pus cells (0-10/HPF) was found in Fosfomycin group compared to (15-20 pus cells/HPF) in Nitofurantoin group, (p-value $=0.002)$. Compliance was $38 / 38(100 \%)$ in Fosfomycin group compared to $34 / 37$ (91.89\%) in Nitrofuantoin group, (p-value $=0.001)$. The common causes of incomplete compliance were multi-dosing and occurrence of side effects. The cost of therapy was slightly higher in fosfomycin group (45 LE) compared to (35 LE) in Nitofurantoin group. This difference was not significant $(\mathrm{p}$-value $=0.342)($ Table 2$)$.

The side effects was recorded in 7 cases (18.42\%) in Fosfomycin group compared to $(35.14 \%)$ with significant difference in the reported side effects, (p-value $=0.003)($ Table 2$)$. The most common side effects for Fosfomycin were diarrhea 11/38 (28.95\%), nausea/vomiting 5/38 (13.16\%) and dizziness 5/38 (13.16\%). In Nitrofuantoin group the most common side effects were diarrhea $14 / 37$ (37.84\%), dyspepsia 12/37 (32.43\%) followed by nausea/vomiting and dizziness in equal number of patients 7/37 (18.92\%) for each side effect (Figure 2).

Resistance was very minimal in Fosfomycin group where 1/38 case (2.63\%) reported resistance for treatment compared to $8 / 37$ cases $(21.62 \%)$ in Nitofurantoin group, ( $\mathrm{p}$-value $=0.001$ ). The cure rate for Fosfomycin group was $97.37 \%$ compared to $78.38 \%$ for Nitofurantoin group, (p-value $=0.002$ ) (Table 2).

\section{Discussion}

Urinary tract infections (UTIs) are common among females; especially pregnant ones due to associated physiological changes that favor the occurrence of UTI. Although pregnancy is a major risk factor for UTI, there are many other contributing factors like, socioeconomic state, diabetes mellitus, recurrent UTI, and other immunologic and blood diseases [14] [15].

UTIs may be presented as asymptomatic bacteruria, cystitis or pyelonephritis with systemic manifestations [16] [17]. Asymptomatic bacteruria should be treated to prevent the occurrence of symptomatic bacteruria as cystitis and pyelonephritis and to prevent its hazards on pregnancy outcomes. At the same time it should be known that asymptomatic bacteruria carries a great risk for development of pre-eclampsia, chorio-amnionitis and preterm delivery [18] [19] [20].

Moreover, repeated urinary tract infection with repeated courses of antibiotic treatment resulted in highly antibiotic resistant bacteria and multi-drug resistant organisms. In addition, the compliance of the patient to take a drug may add a hazard to drug resistant and recurrent infection. So, physicians should shift towards early efficient treatment of UTI in the pregnant females, not only for the health hazards, but also, to decrease progressive UTI during pregnancy which are the most common cause of hospital admissions during pregnancy [21] [22].

It is well known that urine cultures are time and money consuming, contaminated and sometimes antibiotic sensitivity results may be inconvenient with pregnancy; these factors motivate both urologists and obstetricians to begin empirical antibiotic therapy especially in symptomatic patients [17] [23] [24] [25].

Nitrofurantoin and Fosfomycin trometamol are considered the first line of 
Table 2. Efficacy, safety, compliance and cost of treatment options for both groups.

\begin{tabular}{|c|c|c|c|c|}
\hline & $\begin{array}{l}\text { Group I Fosfomycin } \\
\qquad(\mathrm{N}=38)\end{array}$ & $\begin{array}{l}\text { Group II Nitrofurantoin } \\
\qquad(\mathrm{n}=37)\end{array}$ & $\mathrm{X}^{2}$ & $\mathrm{p}$ value \\
\hline Subjective improvement 5 days post treatment & $38 / 38(100 \%)$ & $32 / 37(86.49 \%)$ & 11.390 & $0.030^{*}$ \\
\hline Second urinalysis 7 days after treatment & Pus cells 0 - 10/HPF & Pus cells $15-20 / \mathrm{HPF}$ & 2.334 & $0.002^{*}$ \\
\hline Compliance of patients & $38 / 38(100 \%)$ & $34 / 37(91.89 \%)$ & 2.118 & $0.001^{*}$ \\
\hline Cost of therapy & $45 \mathrm{LE}$ & $36 \mathrm{LE}$ & 2.578 & 0.342 \\
\hline Side effects of drugs & $7 / 38$ patients $(18.42 \%)$ & $13 / 37$ patients $(35.14 \%)$ & 1.209 & 0.003 \\
\hline Resistance & $\begin{array}{c}1 / 38 \text { case }(2.63 \%) \\
\text { One case had } 10 \text { pus cells/HPF in } \\
\text { second urine analysis due to resistance } \\
\text { to Fosfomycin }\end{array}$ & $8 / 37$ cases $(21.62 \%)$ & 7.342 & $0.001^{\star}$ \\
\hline Cure rate & $97.37 \%$ & $78.38 \%$ & 2.007 & $0.002^{*}$ \\
\hline
\end{tabular}

*means significant p-value.

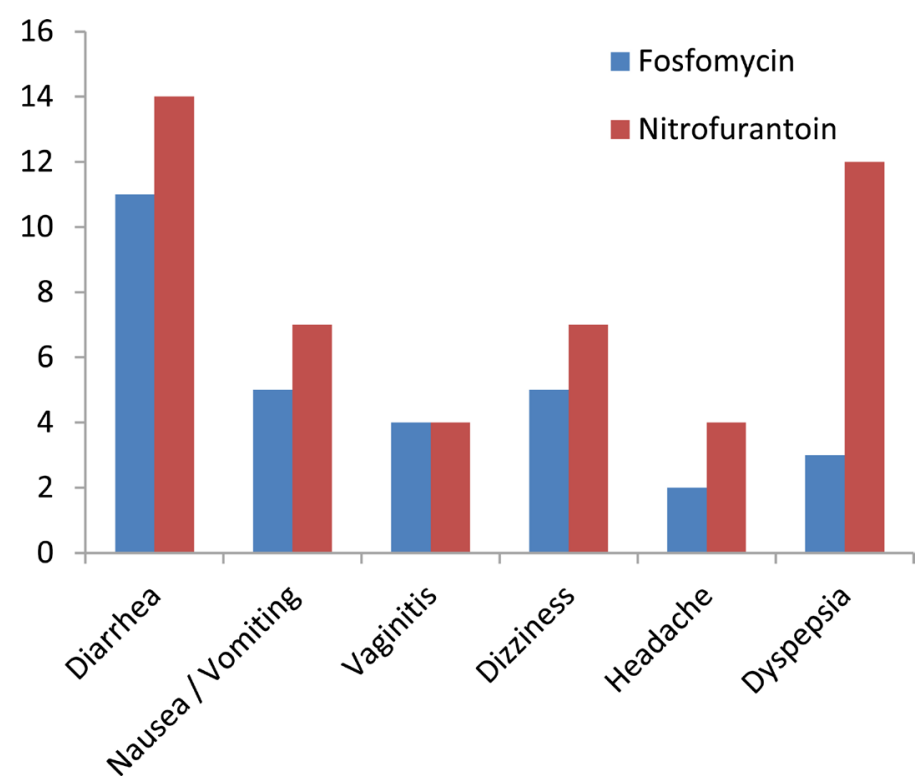

Figure 2. Side effects of drugs tested in the study.

treatment in non-complicated UTI [26]. Nitrofurantoin is a category B drug during pregnancy and commonly prescribed drug for non-complicated UTI during pregnancy [27] [28]. However, there are a lot of concerns about Nitrofurantoin resistance, safety, and patient compliance [29]. Also Nitofurantoin not used during delivery or in near term (i.e. $>36$ weeks) because of the assumed possibility of haemolytic anaemia in the newborn [30].

Fosfomycin trometamol is another category B drug used in single dose and shown stability with decreased appearance of mutant urinary strains overtime in many studies. It has higher efficacy and better compliance over Nitofurantoin and other drugs making it a first choice drug for uncomplicated UTIs In pregnancy [10] [31] [32] [33].

Many studies compared the efficacy and safety of both drugs in uncomplicated UTIs in females but not during pregnancy. Both drugs proved to be safe. 
Side effects were comparable in both groups, but drug compliance was better with Fosfomycin trometamol. Also, subjective and the resolution of infection were better and significantly different in the group of Fosfomycin trometamol [34] [35] [36].

During pregnancy Usta TA, et al. (2011) selected 324 pregnant women with lower urinary tract infection and allocated them randomly into 3 groups, Fosfomycin trometamol, Amoxicilin-calvulinc, and cefuroxime axetil. The treatment groups did not differ significantly in terms of demographics, clinical success rate, microbiological cure rate, or adverse effects. Significantly higher drug compliance was observed in the Fosfomycin trometamol group than in the other 2 groups $(\mathrm{p}<0.05)$. Consequently, they suggested that treatment with a single dose of Fosfomycin trometamol is as effective as the standard course of treatment with Amoxicilin-calvulinc, or cefuroxime axetil, and Fosfomycin trometamol is preferable owing to its simpler use [37].

Liu H-Y, et al. (2011) and Araj GF et al. (2012) showed in vitro susceptibility to Fosfomycin of $86 \%$ - $100 \%$ more than Nitrofuarntoin with comparable results between both groups [38] [39]. These results are comparable to result of this study where persistent infection was found in 1 (2.63\%) case in Fosfomycin group and in $8(21.62 \%)$ cases in Nitrofurantoin group. Similar Fosfomycin resistance of $0 \%-2.2 \%$ to E. coli was reported by Pullukçu H, et al. (2004) and Ko $K S$, et al. (2007) [40] [41].

Although, Ceran N, et al. (2010) showed a comparable results between Fosfomycin and ciprofloxacin with disappearance of pyuria in $80 \%$ of cases, our better results (97.37\% cure with Fosfomycin) could be attributed to less use of Fosfomycin in our locality with less appearance of resistant strains [42]. De Jong et al. (2016) compared Fosfomycin and Norofloxacin in non-pregnant women and they found that the simplified dosage regimen (single dose) and its favorable benefit/risk ratio justify the use of Fosfomycin trometamol as a treatment for uncomplicated urinary tract infections in female patients [43].

Another studies had similar comparable results with Fosfomycin single oral therapy than a longer period's therapy in pregnant females with lower urinary tract infection. Where Krcmery $S$ et al. (2001) showed eradication rate of UTI in 95.2\% and Bayrak et al. (2007) showed eradication rate of 93.2\% with Fosfomycin group [44] [45].

In the present study, although both drugs were tolerable orally, complications occurred less frequently with Fosfomycin group $18.42 \%$ vs $35.14 \%$. Diarrhea was the commonest complication in Fosfomycin group. This was comparable to other studies by Ceran $N$ et al. (2010) [42], Sastry et al. (2015) [46], Meier et al (2011) [47] and Mody et al. (2014). [48] The minor side effects of Fosfomycin were confirmed by Bayrak et al. (2007), who revealed associated minor side effects with Fosfomycin [45].

At last, the compliance of both drugs was better in Fosfomycin group 100\% versus $91.8 \%$ in Nitrofurantoin group. This high compliance with Fosfomycin is greatly attributed to the single administered dose in opposite to the need of 7 
days of Nitrofurantoin.

\section{Limitations of the Study}

The small sample size and the financial costs of drugs-being self-funded-were the main limitations of the study.

\section{Conclusion}

Owing to the higher safety, efficacy, low resistance for Fosfomycin trometamine in management of uncomplicated UTIs during pregnancy, we recommend its wide use at Tanta University Hospitals and to replace other antibiotic regimens as it is cost-effective than other drugs. Moreover, very high patient compliance, fewer side effects were observed with Fosfomycin than other drugs making it a first choice at our hospitals.

\section{Acknowledgements}

Authors want to thank residents of urology and obstetrics and gynecology for their great cooperation, follow up, registration and guidance of cases.

\section{Conflicts of Interests}

No conflicts of interest of any kind do exist.

\section{Author Contributions}

Ayman Shehatadawood: Was responsible for scientific writing, revisions and submission. Abdel-Ghaffar Said Dawood: Was responsible for statistical analysis, writing and revisions. Salah Naglah: Was responsible for data collection, analysis, scientific writing and revisions. Mohamed Elbakary: Was responsible for data collection, analysis, scientific writing and revisions.

\section{References}

[1] Colgan, R. and Williams, M. (2011) Diagnosis and Treatment of Acute Uncomplicated Cystitis. American Family Physician, 84, 771-776.

[2] Hooton, T.M. (2012) Uncomplicated Urinary Tract Infection. The New England Journal of Medicine, 366, 1028-1037. https://doi.org/10.1056/NEJMcp1104429

[3] Gupta, K., Hooton, T.M., Naber, K.G., et al. (2011) International Clinical Practice Guidelines for the Treatment of Acute Uncomplicated Cystitis and Pyelonephritis in Women: A 2010 Update by the Infectious Diseases Society of America and the European Society for Microbiology and Infectious Diseases. Clinical Infectious Diseases, 52, e103-e120. https://doi.org/10.1093/cid/ciq257

[4] Naber, K.G., Schito, G., Botto, H., et al. (2008) Surveillance Study in Europe and Brazil on Clinical Aspects and Antimicrobial Resistance Epidemiology in Females with Cystitis (ARESC): Implications for Empiric Therapy. European Urology, 54, 1164-1175. https://doi.org/10.1016/j.eururo.2008.05.010

[5] Adler, A., Katz, D. and Marchaim, D. (2016) The Continuing Plague of ExtendedSpectrum $\beta$-Lactamase-Producing Enterobacteriaceae Infections. Infectious Disease Clinics of North America, 30, 347-375. https://doi.org/10.1016/j.idc.2016.02.003 
[6] Doi, Y., Park, Y., Rivera, J., Adams-Haduch, J., Hingwe, A., Sordillo, E., Lewis, J., Howard, W., Johnson, L., Polsky, B., Jorgensen, J., Richte, S., Shutt, K. and Paterson, D. (2013) Community-Associated Extended-Spectrum $\beta$-Lactamase-Producing Escherichia coli Infection in the United States. Clinical Infectious Diseases, 56, 641648. https://doi.org/10.1093/cid/cis942

[7] The Center for Disease Control. Antimicrobial/Antibiotic Resistance: Biggest Threats. http://www.cdc.gov/drugresistance/biggest_threats.html

[8] Falagas, M., Kastoris, A., Kapaskelis, A. and Karageorgopoulos, D. (2010) Fosfomycin for the Treatment of Multidrug-Resistant, Including Extended-Spectrum Beta-Lactamase Producing Enterobacteriaceae Infections: A Systemic Review. The Lancet Infectious Diseases, 10, 43-50. https://doi.org/10.1016/S1473-3099(09)70325-1

[9] Lob, S., Nicolle, L., Hoban, D., Kazmierczak, K., Badal, R. and Sahm, D. (2016) Susceptibility Patterns and ESBL Rates of Escherichia from Urinary Tract Infections in Canada and the United States, SMART 2010-2014. Diagnostic Microbiology and Infectious Disease, 85, 459-465. https://doi.org/10.1016/j.diagmicrobio.2016.04.022

[10] Khawaja, A., Khan, F., Dar, T., Bhat, A., Wani, M. and Wazir, B. (2015) Fosfomycin Tromethamine. Antibiotic of Choice in the Female Patient: A Multicenter Study. Central European Journal of Urology, 68, 371-375.

[11] Vardakas, K., Legakis, N., Triarides, N. and Falgas, M. (2016) Susceptibility of Contemporary Isolates to Fosfomycin: A Systemic Review of the Literature. International Journal of Antimicrobial Agents, 47, 269-285. https://doi.org/10.1016/j.ijantimicag.2016.02.001

[12] Estebanez, A., Pascual, R., Gil, V., Ortiz, F., Santibáñez, M. and Pérez Barba, C. (2009) Fosfomycin in a Single Dose versus a 7-Day Course of Amoxicillin-Clavulanate for the Treatment of Asymptomatic Bacteriuria during Pregnancy. European Journal of Clinical Microbiology \& Infectious Diseases, 28, 1457-1464. https://doi.org/10.1007/s10096-009-0805-6

[13] Hale, S.F. (2013) Can Fosfomycin Treat Multidrug-Resistant UTIs? Medscape, Updated 24 July 2016.

[14] Çelen, Ş., Oruç, A.S., Karayalçin, R., Saygan, S., Ünlü, S., Polat, B. and Danişman, N. (2011) Asymptomatic Bacteriuria and Antibacterial Susceptibility Patterns in an Obstetric Population. ISRN Obstetrics and Gynecology, 2011, Article ID: 721872. https://doi.org/10.5402/2011/721872

[15] Glaser, A. and Schaeffer, A. (2015) Urinary Tract Infection and Bacteriuria in Pregnancy. Urologic Clinics of North America, 42, 547-560.

[16] Meads, C. (2011) Screening for Asymptomatic Bacteriuria in Pregnancy: External Review against Programme Appraisal Criteria for the UK National Screening Committee (UK NSC). UK National Screening Committee.

[17] Schnarr, J. and Smaill, F. (2008) Asymptomatic Bacteriuria and Symptomatic Urinary Tract Infections in Pregnancy. European Journal of Clinical Investigation, 38, 50-57. https://doi.org/10.1111/j.1365-2362.2008.02009.x

[18] Bilano, V.L., Ota, E., Ganchimeg, T., Mori, R. and Souza, J.P. (2014) Risk Factors of Pre-Eclampsia/Eclampsia and Its Adverse Outcomes in Low- and Middle-Income Countries: A WHO Secondary Analysis. PLOS ONE, 9, e91198. https://doi.org/10.1371/journal.pone.0091198

[19] Allen, V.M., Yudin, M.H., Bouchard, C., Boucher, M., Caddy, S., Castillo, E., Money, D.M., Murphy, K.E., Ogilvie, G., Paquet, C., van Schalkwyk, J. and Senikas, V., Infectious Diseases Committee, Society of Obstetricians and Gynaecologists of Canada (2012) Management of Group B Streptococcal Bacteriuria in Pregnancy. 
Journal of Obstetrics and Gynaecology Canada, 34, 482-486. https://doi.org/10.1016/S1701-2163(16)35246-X

[20] Randis, T.M., Gelber, S.E., Hooven, T.A., Abellar, R.G., Akabas, L.H., Lewis, E.L., Walker, L.B., Byland, L.M., Nizet, V. and Ratner, A.J. (2014) Group B Streptococcus $\beta$-Hemolysin/Cytolysin Breaches Maternal-Fetal Barriers to Cause Preterm Birth and Intrauterine Fetal Demise in Vivo. The Journal of Infectious Diseases, 210, 265 273. https://doi.org/10.1093/infdis/jiu067

[21] Minardi, D., d'Anzeo, G., Cantoro, D., Conti, A. and Muzzonigro, G. (2011) Urinary Tract Infections in Women: Etiology and Treatment Options. International Journal of General Medicine, 4, 333-343. https://doi.org/10.2147/IJGM.S11767

[22] Guinto, V.T., De Guia, B., Festin, M.R. and Dowswell, T. (2010) Different Antibiotic Regimens for Treating Asymptomatic Bacteriuria in Pregnancy. The Cochrane Database of Systematic Reviews, No. 9, CD007855.

https://doi.org/10.1002/14651858.cd007855.pub2

[23] Unlu, B.S., Yildiz, Y., Keles, I., Kaba, M., Kara, H., Tasin, C., Erkilinc, S. and Yildirim, G. (2014) Urinary Tract Infection in Pregnant Population, Which Empirical Antimicrobial Agent Should Be Specified in Each of the Three Trimesters? Ginekologia Polska, 85, 371-376. https://doi.org/10.17772/gp/1744

[24] Schneeberger, C., van den Heuvel, E.R., Erwich, J.J., et al. (2013) Contamination Rates of Three Urine-Sampling Methods to Assess Bacteriuria in Pregnant Women. Obstetrics \& Gynecology, 121, 299-305.

[25] (2010) HPA and Association of Medical Microbiologists. Management of Infection Guidance for Primary Care for Consultation and Local Adaptation. www.hpa.org.uk

[26] Stiller, R.J., Hicks, C. and Saul, Z. (2017) Treating UTIs in the Age of Antibiotic Resistance: Strategies for the Practicing OB/GYN. Contemporary OB/GYN.

[27] Lumbiganon, P., Villar, J. and Laopaiboon, M. (2009) One-Day Compared with 7-Day Nitrofurantoin for Asymptomatic Bacteriuria in Pregnancy: A Randomized Controlled Trial. Obstetrics \& Gynecology, 113, 339-345.

https://doi.org/10.1097/AOG.0b013e318195c2a2

[28] (2009) Furadantin (Nitrofurantoin) Oral Suspension [Prescribing Information]. Sciele Pharma, Inc., Atlanta, GA.

http://www.accessdata.fda.gov/drugsatfda_docs/label/2009/009175s037lbl.pdf

[29] American College of Obstetricians and Gynecologists (2011) Committee Opinion No. 494: Sulfonamides, Nitrofurantoin, and Risk of Birth Defects. Obstetrics \& Gynecology, 117, 1484-1485. https://doi.org/10.1097/AOG.0b013e3182238c57

[30] Nordeng, H., Lupattelli, A., Romøren, M. and Koren, G. (2013) Neonatal Outcomes after Gestational Exposure to Nitrofurantoin. Obstetrics \& Gynecology, 121, $306-$ 313. https://doi.org/10.1097/AOG.0b013e31827c5f88

[31] Bader, M.S., Loeb, M. and Brooks, A.A. (2017) An Update on the Management of Urinary Tract Infections in the Era of Antimicrobial Resistance. Postgraduate Medicine, 129, 242-258. https://doi.org/10.1080/00325481.2017.1246055

[32] Keating, G.M. (2013) Fosfomycin Trometamol: A Review of Its Use as a SingleDose Oral Treatment for Patients with Acute Lower Urinary Tract Infections and Pregnant Women with Asymptomatic Bacteriuria. Drugs, 73, 1951-1966. https://doi.org/10.1007/s40265-013-0143-y

[33] Zhanel, G.G., Walkty, A.J. and Karlowsky, J.A. (2016) Fosfomycin: A First-Line Oral Therapy for Acute Uncomplicated Cystitis. Canadian Journal of Infectious Diseases \& Medical Microbiology, 2016, Article: ID 2082693.

https://doi.org/10.1155/2016/2082693 
[34] Honderlick, P., Cahen, P., Gravisse, J., et al. (2006) Uncomplicated Urinary Tract Infections, What about Fosfomycin and Nitrofurantoin in 2006? Pathologie Biologie (Paris), 54, 462-466. https://doi.org/10.1016/j.patbio.2006.07.016

[35] Stein, G.E. (1999) Comparison of Single-Dose Fosfomycin and a 7-Day Course of Nitrofurantoin in Female Patients with Uncomplicated Urinary Tract Infection. Clinical Therapeutics, 21, 1864-1872. https://doi.org/10.1016/S0149-2918(00)86734-X

[36] Ruxer, J., Możdżan, M., Siejka, A., Loba, J. and Markuszewski, L. (2006) Fosfomycin and Nitrofurantoin in the Treatment of Recurrent Urinary Tract Infections in Type 2 Diabetic Women: A Preliminary Report. Diabetologia Doświadczalna i Kliniczna, 6, 277-282.

[37] Usta, T.A., Dogan, O., Ates, U., et al. (2011) Comparison of Single-Dose and Multiple-Dose Antibiotics for Lower Urinary Tract Infection in Pregnancy. International Journal of Gynecology \& Obstetrics, 114, 229-233. https://doi.org/10.1016/j.ijgo.2011.03.014

[38] Liu, H.-Y., Lin, H.-C., Lin, Y.-C., et al. (2011) Antimicrobial Susceptibilities of Urinary Extended-Spectrum Beta-Lactamase-Producing Escherichia coli and Klebsiella pneumoniae to Fosfomycin and Nitrofurantoin in a Teaching Hospital in Taiwan. Journal of Microbiology, Immunology and Infection, 44, 364-368. https://doi.org/10.1016/j.jmii.2010.08.012

[39] Araj, G.F. and Jaber, F.A. (2012) In Vitro Activity of Fosfomycin and Other Antimicrobials against Uropathogenic Escherichia coli and Klebsiella pneumoniae at a Tertiary Care Center in Lebanon. Lebanese Medical Journal, 60, 142-147.

[40] Pullukçu, H., Aydemir, S., Işikgöz Taşbakan, I., et al. (2013) Is There a Rise in Resistance Rates to Fosfomycin and Other Commonly Used Antibiotics in Escherichia coli-Mediated Urinary Tract Infections? A Perspective for 2004-2011. Turkish Journal of Medical Sciences, 43, 537-541. https://doi.org/10.3906/sag-1210-75

[41] Ko, K.S., Suh, J.Y., Peck, K.R., et al. (2007) In Vitro Activity of Fosfomycin against Ciprofloxacin-Resistant or Extended-Spectrum $\beta$-Lactamase-Producing Escherichia coli Isolated from Urine and Blood. Diagnostic Microbiology and Infectious Disease, 58, 111-115. https://doi.org/10.1016/j.diagmicrobio.2006.11.015

[42] Ceran, N., Mert, D., Kocdogan, F.Y., et al. (2010) A Randomized Comparative Study of Single-Dose Fosfomycin and 5-Day Ciprofloxacin in Female Patients with Uncomplicated Lower Urinary Tract Infections. Journal of Infection and Chemotherapy, 16, 424-430. https://doi.org/10.1007/s10156-010-0079-z

[43] De Jong, Z., Pontonnier, F. and Plante, P. (1991) Single-Dose Fosfomycin Trometamol (Monuril) versus Multiple-Dose Norfloxacin: Results of a Multicenter Study in Females with Uncomplicated Lower Urinary Tract Infections. Urologia Internationalis, 46, 344-348. https://doi.org/10.1159/000282164

[44] Krcmery, S., Hromec, J. and Demesova, D. (2001) Treatment of Lower Urinary Tract Infection in Pregnancy. International Journal of Antimicrobial Agents, 17, 279-282. https://doi.org/10.1016/S0924-8579(00)00351-4

[45] Bayrak, O., Çimentepe, E., Inegöl, I., et al. (2007) Is Single-Dose Fosfomycin Trometamol a Good Alternative for Asymptomatic Bacteriuria in the Second Trimester of Pregnancy? International Urogynecology Journal, 18, 525-529. https://doi.org/10.1007/s00192-006-0190-y

[46] Sastry, S., Clarke, L.G., Alrowais, H., Querry, A.M., Shutt, K.A. and Doi, Y. (2015) Clinical Appraisal of Fosfomycin in the Era of Antimicrobial Resistance. Antimicrobial Agents and Chemotherapy, 59, 7355-7361.

https://doi.org/10.1128/AAC.01071-15 
[47] Meier, S., Weber, R., Zbinden, R., Ruef, C. and Hasse, B. (2011) Extended-Spectrum $\beta$-Lactamase-Producing Gram-Negative Pathogens in Community-Acquired Urinary Tract Infections: An Increasing Challenge for Antimicrobial Therapy. Infection, 39, 333-340. https://doi.org/10.1007/s15010-011-0132-6

[48] Mody, L. and Juthani-Mehta, M. (2014) Urinary Tract Infections in Older Women: A Clinical Review. JAMA, 311, 844-854. https://doi.org/10.1001/jama.2014.303

\section{Appendix I}

Tanta University

Faculty of Medicine

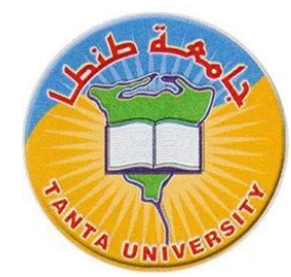

Questionnaire form

Section 1: Demographic data

- Name:

- Age:

- Residence:

- Gravidity/Parity:

- BMI:

Section 2: Patient Presentation

- Gestational age:

- First Urine analysis findings:

- Ultrasound findings:

- Symptoms improvement:

Complete improvement

Partial improvement

If partial what are the residual symptoms:

- Compliance of patients:

Complete compliance

Incomplete compliance

Causes of incomplete compliance:

- Cost of treatment:

Section 3: Drug efficacy and safety assessment

- Second urine analysis findings:

- Side effects reported: 
Submit or recommend next manuscript to SCIRP and we will provide best service for you:

Accepting pre-submission inquiries through Email, Facebook, LinkedIn, Twitter, etc. A wide selection of journals (inclusive of 9 subjects, more than 200 journals)

Providing 24-hour high-quality service

User-friendly online submission system

Fair and swift peer-review system

Efficient typesetting and proofreading procedure

Display of the result of downloads and visits, as well as the number of cited articles Maximum dissemination of your research work

Submit your manuscript at: http://papersubmission.scirp.org/

Or contact ojog@scirp.org 